\title{
Lactation protects against myocardial ischemia-reperfusion injury in rats
}

\author{
S Shekarforoush ${ }^{1}$, F Safari ${ }^{2}$ \\ ${ }^{1}$ Department of Physiology, Arsanjan Branch, Islamic Azad University, Fars, Iran \\ ${ }^{2}$ Department of Physiology, Shahid Sadoughi University of Medical Sciences, Yazd, Iran
}

Received: August 14, 2014

Accepted: August 26, 2015

\begin{abstract}
Some researchers have reported that lactation is effective in reducing cardiovascular disease risk factors. The purpose of this study was to investigate whether lactation may improve intrinsic tolerance against ischemia reperfusion (IR) injury. The rats were randomly divided into two groups ( $n=8$ in each group). In the lactation (Lact) group, the surgery was performed on postpartum day 21 (at the end of lactation period) and the results were compared with those of virgin female rats (control group). Cardiac IR injury was induced by means of left anterior descending coronary artery occlusion for $30 \mathrm{~min}$ followed by reperfusion for $120 \mathrm{~min}$. Infarct size was measured using the staining agent 2,3,5-triphenyltetrazolium chloride. At the end of the experiment, Mean arterial pressure in the control group was significantly lower than that in the Lact group. Myocardial infarct size was significantly reduced in the Lact group ( $23 \pm 3 \%$ vs. $45 \pm 8 \%, p<0.05$ in the control group). Lactation reduced the extent of myocardial injury induced by ischemia and reperfusion. So, lactation may increase cardiac tolerance to ischemic injury.
\end{abstract}

Keywords: lactation, myocardial ischemia, reperfusion, preconditioning, cardioprotection

Recent researches have indicated that lactation has impacts on maternal health through effects on hypothalamic, autonomic, and cardiovascular functioning both during the breastfeeding period and after weaning. Lactation is associated with increased parasympathetic and decreased sympathetic activity (30), less atherogenic lipid profile and improved fasting glucose (18), decreased risk of developing hypertension (39), the metabolic syndrome (19), and cardiovascular disease. One may speculate that a complex hormonal cascade triggered by lactation can influence a number of different factors like blood pressure regulation, glucose homeostasis and insulin secretion, lipid homeostasis, and inflammatory processes (12).

The tissue damage caused by restoration of blood flow after a period of ischemia is known as ischemia reperfusion (IR) injury. The results from therapeutic targeting of the individual components of lethal myocardial IR injury, including oxidative stress, calcium overload, $\mathrm{pH}$ correction, and inflammation have been disappointing (21). So for several decades, there has been a concerted effort in cardiology to identify interventions to increase the heart resistance to infarction. In 1986, Murry et al. first introduced the concept of "conditioning" the myocardium to protect it against IR injury (32). Exposure to brief periods of ischemia (called ischemic preconditioning [IPC]), prior to prolonged ischemia, has been recognized as a powerful endogenous form of cardioprotection (21). However, this intervention was both invasive and impractical to apply, and non-invasive approaches for protecting the heart were sought such as exposure to a brief limb ischemia (remote IPC) (25),

Corresponding author: Shahnaz Shekarforoush

Arsanjan Branch, Islamic Azad University, Fars, Iran

Phone: +989173376859; Fax:+987297622483; E-mails: shek@iaua.ac.ir; sh.shekar@yahoo.com 
pharmacological agents, hyperoxic environment, exercise and so on. In experimental IR injury models, the protective effect of a wide range of hormones, including oxytocin (34), prolactin (26), estrogen (4), thyroid hormone (33), and endogenous substances, including NO (23), and heat shock proteins (14) including heme oxygenase-1 (24) has been shown. Due to substantial changes in the factors involved in the regulation of cardiovascular function during lactation, the purpose of the present study was to explore whether lactation may protect the heart against ischemia reperfusion (IR) injury in an in vivo rat model.

\section{Materials and Methods}

\section{Animals}

Female Wistar rats (weighing 200-250 g) were housed under standard conditions with free access to food and water. The investigation was approved by the animal and human ethics committee of Islamic Azad University (51601901119002).

\section{Experimental protocols}

The rats were randomly divided into two groups ( $n=8$ in each group). In the Lact group, each female was paired with a male until they looked visibly pregnant. On postpartum day 21 (at the end of lactation period), the rats underwent surgery. In the control group, each female was paired with another female. During this time (almost 42-45 days), virgin control rats were maintained in separate cages and then they underwent surgery. The rat estrous cycle is typically 4-5 days in length. Pregnancy lasts about 21-22 days. The pups are typically weaned by 21 days of age. The serum estradiol level fluctuations during various estrous cycle stages of rats do not influence cardiac IR injury and are not correlated with infarct size or arrhythmia. Because endogenous changes in reproductive hormones do not appear to be a confounding variable in IR studies (15), the serum estradiol level and estrous cycle stages of rats was not assessed.

\section{Surgical procedure}

The procedure used in the present study was described in our previous experiments (37). In brief, the animals were anesthetized with sodium pentobarbital $\left(30 \mathrm{mg} \cdot \mathrm{kg}^{-1}\right)$ and ketamin (50 mg. $\left.\mathrm{kg}^{-1}\right)$ i.p. Rectal temperature was continuously monitored and maintained at $37 \pm$ $0.5^{\circ} \mathrm{C}$. Following tracheotomy, the rats were ventilated with room air enriched with oxygen at a rate of 70 to 80 per min and tidal volume of $1 \mathrm{ml} \cdot \mathrm{kg}^{-1}$ to maintain blood $\mathrm{PO}_{2}, \mathrm{PCO}_{2}$, and $\mathrm{pH}$ in the normal physiological range. A standard limb lead II electrocardiogram (ECG) was monitored and recorded throughout the experiment. Catheters were inserted into the left carotid artery and tail vein (Angiocat 23; Suppa, Tehran, Iran) for monitoring blood pressure and infusion of Evans blue solution, respectively. A left thoracotomy was performed and the pericardium was opened to expose the heart. A 6-0 silk suture was passed around the left anterior descending coronary artery (LAD) and its ends were threaded through a small plastic tube to form a snare. Following a stabilization period of $20 \mathrm{~min}$, the artery was occluded for $30 \mathrm{~min}$ by clamping the snare against the surface of the heart. Ischemia was confirmed by regional cyanosis and ST elevation in the ECG. Reperfusion was established by releasing the snare for $120 \mathrm{~min}$. 
Determination of infarct size and area at risk

At the end of reperfusion, the LAD was re-occluded and $1 \mathrm{ml}$ Evans Blue dye \%1 (Sigma, St. Louis, MO) was injected into the tail vein to identify the area at risk (AAR). The heart was excised, rinsed of excess blue dye, trimmed of the atria and right ventricle, put in a matrix, wrapped in plastic foil and frozen at $-20^{\circ} \mathrm{C}(2 \mathrm{~h})$. The left ventricle (LV) was cut into transverse slices of $2 \mathrm{~mm}$ thickness from the apex to the base. Tissue samples were then incubated in triphenyltetrazolium chloride 1\% [TTC (Sigma)] solution in isotonic phosphated buffer, $\mathrm{pH}=7.4$, for $20 \mathrm{~min}$ at $37^{\circ} \mathrm{C}$, and subsequently fixed in $10 \%$ formalin for $1 \mathrm{~h}$. Viable tissue was stained red by TTC, whereas infarcted tissue remained unstained (white). An image was obtained (canoscan LID 25) from both sides of each slice and all calculations from one heart (using Image Tool Software) were averaged into one value for statistical analysis. The total area at risk was expressed as a percentage of the left ventricles (AAR/LV). Infarct size (IS) was expressed as a percentage of the AAR (IS/AAR).

\section{Assessment of ventricular arrhythmias}

Ischemia-induced ventricular arrhythmias were determined in accordance with the Lambeth conventions (41): premature ventricular complexes (PVCs as a discrete and identifiable premature QRS complex (premature with respect to the $\mathrm{P}$ wave), ventricular tachycardia (VT) as a run of four or more PVC at a rate faster than the resting sinus rate and ventricular fibrillation (VF) as a signal for which individual QRS deflection can no longer be distinguished from one another. Complex forms (bigeminy and salvos) were added to PVCs count and not analyzed separately.

\section{Statistical analysis}

Statistical analysis was carried out using SPSS software (version 16). Data are expressed as mean \pm SEM or as percent. Student's $t$-test or Fisher exact test was used to analyze the data. Values of $P<0.05$ were considered as significant.

\section{Results}

\section{Hemodynamic parameters}

Table I summarizes the hemodynamic data. There were no significant differences at baseline values for heart rate (HR) and mean arterial blood pressure (MAP) between the groups. Ischemia caused a marked decrease in blood pressure. At the end of the experiment, MAP in the control group was significantly lower than that in the Lact group.

Table I. Hemodynamics parameters in experimental groups

\begin{tabular}{|l|c|c|c|c|c|c|}
\hline \multirow{2}{*}{ Groups } & \multicolumn{2}{|c|}{ Baseline } & \multicolumn{2}{c|}{ Ischemia } & \multicolumn{2}{c|}{ Reperfusion } \\
\cline { 2 - 7 } & HR & MBP & HR & MBP & HR & MBP \\
\hline Control & $331 \pm 23$ & $123 \pm 13$ & $341 \pm 23$ & $101 \pm 22^{* *}$ & $326 \pm 16$ & $91 \pm 14^{* * *}$ \\
\hline Lact & $321 \pm 16$ & $124 \pm 13$ & $341 \pm 43$ & $112 \pm 15^{*}$ & $335 \pm 40$ & $111 \pm 14^{*}$ \\
\hline
\end{tabular}

Control $=$ Virgin female rats, Lact $=$ Female rats that completed lactation period after parturition.

$* P<0.05, * * P<0.01$ compared with the baseline values within the same group

${ }^{\#} P<0.05$ compared with other group 


\section{Myocardial infarct size}

The effect of lactation on myocardial infarct size is shown in Fig 1. The size of AAR did not differ between the two groups, indicating equal position of LAD occlusion. Myocardial infarct size was significantly reduced in the Lact group ( $23 \pm 3 \%$ vs. $45 \pm 8 \%, p<0.05)$.

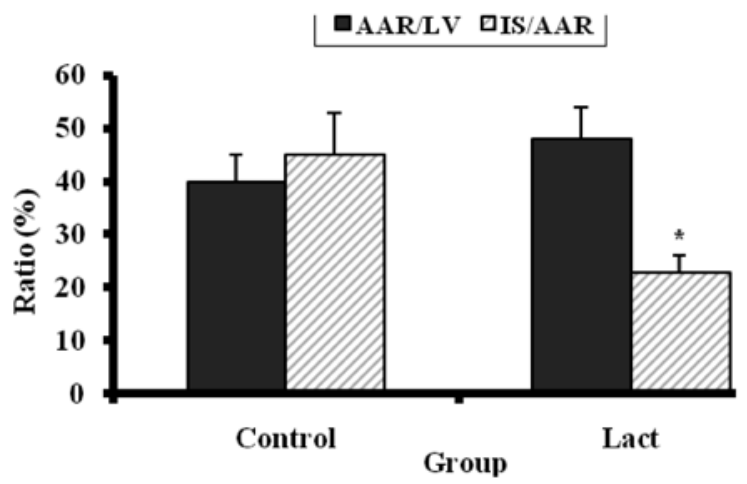

Fig. 1. Infarct size (IS) and area at risk (AAR) following 30-min ischemia and 120-min reperfusion in rats. $\mathrm{LV}=$ left ventricle; $* P<0.05$ compared with the other group. Control $=$ Virgin female rats, Lact $=$ Female rats that completed lactation period after parturition

\section{Ischemia-induced arrhythmias}

The results of lactation on ischemia-induced arrhythmia are shown in Table II. During 30min ischemia, the numbers of PVC, episodes of VT and duration of VT in the control group were $258 \pm 35,31 \pm 6$ and $31 \pm 6 \mathrm{sec}$, respectively. The rate of these arrhythmias in the Lact group was reduced, but it was not significant. VF occurred nearly in $75 \%$ of rats in both groups. A rat (in the control group) died due to irreversible VF during ischemia. Mortality rate did not differ in this relatively small sample. There were no considerable reperfusion induced arrhythmias in the present work.

Table II. Incidence of ventricular arrhythmias during $30 \mathrm{~min}$ of ischemia in the Control and Lact groups

\begin{tabular}{|l|c|c|c|c|}
\hline & PVC (n) & VT (n) & VT duration (sec) & VF (\%) \\
\hline Control group & $258 \pm 35$ & $31 \pm 6$ & $31 \pm 6$ & $77.8 \%$ \\
\hline Lact group & $236 \pm 30$ & $28 \pm 5$ & $23 \pm 6$ & $75 \%$ \\
\hline
\end{tabular}

The numbers of premature ventricular complexes (PVC), the episodes of ventricular tachycardia (VT), and VT duration (as means \pm SEM) and the incidence of ventricular fibrillation (VF) (as percent) are shown. Control $=$ Virgin female rats, Lact $=$ Female rats that completed lactation period after parturition

\section{Discussion}

The main findings of this study were: 1) A significant decrease in infarct size (IS) following 30-min of ischemia and 120 min of reperfusion was observed in the Lact group, 2) At the end of the lactation period, no significant changes were observed in hemodynamic parameters compared to the control group, 3) Ischemia induced arrhythmias were reduced in the Lact group, but no statistical significance was reached. 
The incidence of ventricular arrhythmia, infarct size, and mortality positively correlated with the size of the ischemic area in animal models $(6,10)$. In this study, as in previous studies (8), VF occurred as a self-limited arrhythmia in $75 \%$ of rats in both groups. However, a rat (in the control group) died due to irreversible VF during ischemia.

The concept of therapeutic infarct size limitation was first promoted by Maroka et al. (29). Myocardial salvage is a potential strong endpoint for success in acute reperfused myocardial infarction (20). Our study indicated that the lactation can provide cardiac protection against IR injury by decreasing IS. Consistent with our findings, Faltová et al. showed that in lactating mothers the extent of isoprenaline-induced heart lesions and mortality were significantly decreased; moreover, the resistance of the right ventricle to anoxia was higher than that of virgin females (13).

The effect of lactation in IR injury model has not been studied so far. To our knowledge, this is the first animal experimental demonstration showing that lactation can mimic preconditioning. There were no significant changes in basal hemodynamic values on postpartum day 21 . So, the protective effect of lactation on the myocardium is not related to alterations in hemodynamic parameters. It is a new benefit of breastfeeding in encouraging mothers to choose nursing.

Some clinical studies have established that there is a dose-dependent relationship between lactation and reduced risk of coronary heart disease $(12,36)$. Although the mechanisms are still debated, it has been hypothesized that lactation may influence several pituitary hormones and induce even long-term changes in the hypothalamic-pituitary axis (12). After parturition, large quantities of prolactin and oxytocin (OT) are released from the pituitary gland into the circulation in response to a suckling stimulus. Principal site of prolactin is the mammary gland. Few studies have investigated the potential role of prolactin in the increased risk of cardiovascular events, e.g. essential hypertension, the heart failure that accompanies Peripartum cardiomyopathy, and arrhythmias $(7,22)$. On the other hand, the positive influence of prolactin on the cardiovascular system was shown. Results of a study showed that administration of supraphysiological doses of prolactin isoforms could protect against sudden cardiac death as well as severe arrhythmias episodes during reperfusion (26). In general, experimental data and clinical observations remain contradictory.

OT synthesis and receptors are found in cardiac and vascular tissue (17). It has been reported that lactation alters maternal cardiovascular function, possibly through the actions of OT (31). Favourable effects of lactation on blood pressure have been attributed to OT (28). In animal models, the administration of OT leads to decreased blood pressure (35) and a reduction of myocardial infarct size in the rat (34). In addition, blockade of OT receptors by atosiban abrogates the cardioprotective effects of IPC (1).

The cardioprotective effects of glucocorticoids and adrenocorticotropin in IR injury have been experimentally demonstrated in animals $(5,40)$ and humans (16). Although a decline in the serum cortisol and adrenocorticotropin concentrations in the breast feeding women was found (2), there is a positive association between duration of lactation and cortisol levels in postmenopausal women (27), that means that both increased cortisol levels and increased duration of breast-feeding have protective roles in the cardiovascular system.

The release of OT and prolactin during suckling is associated with the vagus nerve activity (11). The results of previous studies have shown that vagus nerve stimulation (VNS) offers protection against ischemic brain (3) and myocardial (38) injury. The researchers found that cardioprotective effects of VNS including reduced infarct size and decreased 
ventricular fibrillation episodes were abolished by muscarinic blockade (38). On the other hand, the protective signal of remote IPC reaches the heart through the vagus nerve and activation of muscarinic receptors (9).

Together these data suggest that lactation by a wide range of hormones and different pathways creates protective alterations in the cardiovascular function that have not yet been revealed. So, the mechanisms causing this protection remain to be explored. Also, it is necessary to reproduce this experiment to identify whether lactation also creates protection for other tissues against IR injury. The duration of the protective effect of lactation after weaning should also be determined. Future research is needed for the comparison of maternal females with and without breastfeeding.

In summary, lactation reduced the extent of myocardial injury induced by ischemia and reperfusion. So, there is evidence that lactation may increase cardiac tolerance to ischemic injury and is considered to be as a preconditioning stimulus in the lactating mothers.

\section{Acknowledgement}

This research work was supported by a grant no. 51601901119002 from the Islamic Azad University, Arsanjan Branch.

\section{REFERENCES}

1. Alizadeh AM, Faghihi M, Sadeghipour HR, Mohammadghasemi F, Khori V: Role of endogenous oxytocin in cardiac ischemic preconditioning. Regul. Pept. 167, 86-90 (2011)

2. Amico JA, Johnston JM, Vagnucci AH: Suckling-induced attenuation of plasma cortisol concentrations in postpartum lactating women. Endocr. Res. 20, $79-87$ (1994)

3. Ay I, Sorensen AG, Ay H: Vagus nerve stimulation reduces infarct size in rat focal cerebral ischemia: An unlikely role for cerebral blood flow. Brain Res. 1392, 110-115 (2011)

4. Babiker FA, Hoteit LJ, Joseph S, Mustafa AS, Juggi JS: The role of 17-beta estradiol in ischemic preconditioning protection of the heart. Exp. Clin. Cardiol. 17, 95-100 (2012)

5. Bazzani C, Guarini S, Botticelli AR, Zaffe D, Tomasi A, Bini A, Cainazzo MM, Ferrazza G, Mioni C, Bertolini A: Protective effect of melanocortin peptides in rat myocardial ischemia. J. Pharmacol. Exp. Ther. 297, 10821087 (2001)

6. Bolli R, Fisher DJ, Entman ML: Factors that determine the occurrence of arrhythmias during acute myocardial ischemia. Am. Heart J. 111, 261-270 (1986)

7. Carrero JJ, Kyriazis J, Sonmez A, Tzanakis I, Qureshi AR, Stenvinkel P, Saglam M, Stylianou K, Yaman H, Taslipinar A, Vural A, Gok M, Yenicesu M, Daphnis E, Yilmaz MI: Prolactin levels, endothelial dysfunction, and the risk of cardiovascular events and mortality in patients with CKD. Clin. J. Am. Soc. Nephrol. 7, 207-215 (2012)

8. del Monte F, Lebeche D, Guerrero JL, Tsuji T, Doye AA, Gwathmey JK, Hajjar RJ: Abrogation of ventricular arrhythmias in a model of ischemia and reperfusion by targeting myocardial calcium cycling. Proc. Natl Acad. Sci. U. S. A. 101, 5622-5627 (2004)

9. Donato M, Buchholz B, Rodriguez M, Perez V, Inserte J, Garcia-Dorado D, Gelpi RJ: Role of the parasympathetic nervous system in cardioprotection by remote hindlimb ischaemic preconditioning. Exp. Physiol. 98, 425-434 (2013)

10. Endo T, Kiuchi K, Sato N, Hayakawa H, Okumura H: Does the extent of the zone at risk after coronary artery occlusion influence the percentage of the zone that evolves to infarction? Cardiology 77, 112-120 (1990)

11. Eriksson M, Bjorkstrand E, Smedh U, Alster P, Matthiesen AS, Uvnas-Moberg K: Role of vagal nerve activity during suckling. Effects on plasma levels of oxytocin, prolactin, VIP, somatostatin, insulin, glucagon, glucose and of milk secretion in lactating rats. Acta Physiol. Scand. 151, 453-459 (1994) 
12. Fagerhaug TN, Forsmo S, Jacobsen GW, Midthjell K, Andersen LF, Ivar Lund Nilsen T: A prospective population-based cohort study of lactation and cardiovascular disease mortality: the HUNT study. BMC Public Health 13, 1070 (2013)

13. Faltová E, Mraz M, Prochazka J, Sedivy J: The effect of pregnancy and lactation on the development of experimental heart lesions. Physiol. Bohemoslov. 29, 305-312 (1980)

14. Fan GC, Ren X, Qian J, Yuan Q, Nicolaou P, Wang Y, Jones WK, Chu G, Kranias EG: Novel cardioprotective role of a small heat-shock protein, Hsp20, against ischemia/reperfusion injury. Circulation 111, 1792-1799 (2005)

15. Frasier CR, Brown DA, Sloan RC, Hayes B, Stewart LM, Patel HD, Lust RM, Rosenbaum MD: Stage of the estrous cycle does not influence myocardial ischemia-reperfusion injury in rats (Rattus norvegicus). Comp. Med. 63, 416-421 (2013)

16. Giugliano GR, Giugliano RP, Gibson CM, Kuntz RE: Meta-analysis of corticosteroid treatment in acute myocardial infarction. Am. J. Cardiol. 91, 1055-1059 (2003)

17. Grewen KM, Light KC: Plasma oxytocin is related to lower cardiovascular and sympathetic reactivity to stress. Biol. Psychol. 87, 340-349 (2011)

18. Gunderson EP, Hedderson MM, Chiang V, Crites Y, Walton D, Azevedo RA, Fox G, Elmasian C, Young S, Salvador N, Lum M, Quesenberry CP, Lo JC, Sternfeld B, Ferrara A, Selby JV: Lactation intensity and postpartum maternal glucose tolerance and insulin resistance in women with recent GDM: the SWIFT cohort. Diabetes Care 35, 50-56 (2012)

19. Gunderson EP, Jacobs DR, Chiang V, Lewis CE, Feng J, Quesenberry CP, Sidney S: Duration of lactation and incidence of the metabolic syndrome in women of reproductive age according to gestational diabetes mellitus status: a 20-year prospective study in CARDIA (Coronary Artery Risk Development in Young Adults). Diabetes 59, 495-504 (2010)

20. Hadamitzky M, Langhans B, Hausleiter J, Sonne C, Kastrati A, Martinoff S, Schomig A, Ibrahim T: The assessment of area at risk and myocardial salvage after coronary revascularization in acute myocardial infarction: comparison between CMR and SPECT. JACC Cardiovasc. Imaging 6, 358-369 (2013)

21. Hausenloy DJ, Yellon DM: Myocardial ischemia-reperfusion injury: a neglected therapeutic target. J. Clin. Invest. 123, 92-100 (2013)

22. Hilfiker-Kleiner D, Sliwa K: Pathophysiology and epidemiology of peripartum cardiomyopathy. Nat. Rev. Cardiol. 11, 364-370 (2014)

23. Jones SP, Bolli R: The ubiquitous role of nitric oxide in cardioprotection. J. Mol. Cell Cardiol. 40, 16-23 (2006)

24. Juhasz B, Varga B, Czompa A, Bak I, Lekli I, Gesztelyi R, Zsuga J, Kemeny-Beke A, Antal M, Szendrei L, Tosaki A: Postischemic cardiac recovery in heme oxygenase-1 transgenic ischemic/reperfused mouse myocardium. J. Cell Mol. Med. 15, 1973-1982 (2011)

25. Kharbanda RK, Mortensen UM, White PA, Kristiansen SB, Schmidt MR, Hoschtitzky JA, Vogel M, Sorensen $\mathrm{K}$, Redington AN, MacAllister R: Transient limb ischemia induces remote ischemic preconditioning in vivo. Circulation 106, 2881-2883 (2002)

26. Krzeminski TF, Mitrega K, Porc M, Zorniak M, Ryszka F, Ostrowska Z, Kos-Kudla B: Differential action of two prolactin isoforms on ischemia and re-perfusion-induced arrhythmias in rats in vivo. J. Endocrinol. Invest. 34, 206-215 (2011)

27. Lankarani-Fard A, Kritz-Silverstein D, Barrett-Connor E, Goodman-Gruen D: Cumulative duration of breastfeeding influences cortisol levels in postmenopausal women. J. Womens Health Gend. Based Med. 10, 681-687 (2001)

28. Light KC, Grewen KM, Amico JA, Brownley KA, West SG, Hinderliter AL, Girdler SS: Oxytocinergic activity is linked to lower blood pressure and vascular resistance during stress in postmenopausal women on estrogen replacement. Horm. Behav. 47, 540-548 (2005)

29. Maroko PR, Kjekshus JK, Sobel BE, Watanabe T, Covell JW, Ross J, Braunwald E: Factors influencing infarct size following experimental coronary artery occlusions. Circulation 43, 67-82 (1971)

30. Mezzacappa ES, Kelsey RM, Katkin ES: Breast feeding, bottle feeding, and maternal autonomic responses to stress. J. Psychosom. Res. 58, 351-365 (2005)

31. Mezzacappa ES, Kelsey RM, Myers MM, Katkin ES: Breast-feeding and maternal cardiovascular function. Psychophysiology 38, 988-997 (2001)

32. Murry CE, Jennings RB, Reimer KA: Preconditioning with ischemia: a delay of lethal cell injury in ischemic myocardium. Circulation 74, 1124-1136 (1986)

33. Nicolini G, Pitto L, Kusmic C, Balzan S, Sabatino L, Iervasi G, Forini F: New insights into mechanisms of cardioprotection mediated by thyroid hormones. J. Thyroid Res. 2013, 264-387 (2013) 
34. Ondrejcakova M, Ravingerova T, Bakos J, Pancza D, Jezova D: Oxytocin exerts protective effects on in vitro myocardial injury induced by ischemia and reperfusion. Can. J. Physiol. Pharmacol. 87, 137-142 (2009)

35. Petersson M, Uvnas-Moberg K: Postnatal oxytocin treatment of spontaneously hypertensive male rats decreases blood pressure and body weight in adulthood. Neurosci. Lett. 440, 166-169 (2008)

36. Schwarz EB, Ray RM, Stuebe AM, Allison MA, Ness RB, Freiberg MS, Cauley JA: Duration of lactation and risk factors for maternal cardiovascular disease. Obstet. Gynecol. 113, 974-982 (2009)

37. Shekarforoush S, Foadoddini M: Cardiac effects of cupping: myocardial infarction, arrhythmias, heart rate and mean arterial blood pressure in the rat heart. Chin. J. Physiol. 55, 253-258 (2012)

38. Shinlapawittayatorn K, Chinda K, Palee S, Surinkaew S, Thunsiri K, Weerateerangkul P, Chattipakorn S, KenKnight BH, Chattipakorn N: Low-amplitude, left vagus nerve stimulation significantly attenuates ventricular dysfunction and infarct size through prevention of mitochondrial dysfunction during acute ischemia-reperfusion injury. Heart Rhythm 10, 1700-1707 (2013)

39. Stuebe AM, Schwarz EB, Grewen K, Rich-Edwards JW, Michels KB, Foster EM, Curhan G, Forman J: Duration of lactation and incidence of maternal hypertension: a longitudinal cohort study. Am. J. Epidemiol. 174, 11471158 (2011)

40. Valen G, Kawakami T, Tahepold P, Dumitrescu A, Lowbeer C, Vaage J: Glucocorticoid pretreatment protects cardiac function and induces cardiac heat shock protein 72. Am. J. Physiol. Heart Circ. Physiol. 279, H836-843 (2000)

41. Walker MJ, Curtis MJ, Hearse DJ, Campbell RWF, Janse MJ, Yellon DM, Cobbe SM: The Lambeth conventions: Guidelines for the study of arrhythmias in ischemia infarction and reperfusion. Cardiovasc. Res. 22, 447-455 (1988) 